\title{
Characterization of Shiga toxin-producing Escherichia coli 0130:H11 and 0178:H19 isolated from dairy cows
}

\author{
Daniel Fernández, Alejandra Krüger, Rosana Polifroni, Ana V. Bustamante, A. Mariel Sanso, \\ Analía I. Etcheverría, Paula M. A. Lucchesi, Alberto E. Parma and Nora L. Padola*
}

Laboratorio de Inmunoquímica y Biotecnología, Facultad Ciencias Veterinarias, Centro de Investigaciones Veterinarias Tandil-Consejo Nacional de Investigaciones Científicas y Técnicas-Comisión de Investigaciones Científicas de la Provincia de Buenos Aires (CIVETAN-CONICET-CICPBA), Universidad Nacional del Centro de la Provincia de Buenos Aires, Tandil, Argentina

\section{Edited by:}

Rey Carabeo, Imperial College London, UK

\section{Reviewed by:}

Jorge Giron, University of Florida, USA

Gunnar N. Schroeder, Imperial College London, UK

\section{*Correspondence:}

Nora L. Padola, Laboratorio de Inmunoquímica y Biotecnología, Departamento SAMP, Centro de

Investigaciones Veterinarias Tandil-Consejo Nacional de Investigaciones Cientificas y Técnicas-Comisión de

Investigaciones Científicas de la Provincia de Buenos Aires (CIVETAN-CONICET-CICPBA), Universidad Nacional del Centro de la Provincia de Buenos Aires, Pinto 399, Tandil, Buenos Aires, B7000, Argentina.

e-mail:nlpadola@vet.unicen.edu.ar
Shiga toxin-producing E. coli (STEC) are isolated from human patients with bloody diarrhea, hemorrhagic colitis $(\mathrm{HC})$, and hemolytic uremic syndrome (HUS). In the last years, the infections with non-0157 serotypes are increasing their frequency of association with human disease. STEC produce Shiga toxin (Stx) and other virulence factors that could contribute to human pathogenesis. Cattle are the main reservoir and the transmission to humans is through the consumption of undercooked meat, non-pasteurized dairy products, and vegetables or water contaminated with feces. We have previously determined that 0130:H11 and 0178:H19 serotypes were the most prevalent in dairy cows from Argentina. In the present study, 37 and 25 STEC isolates from dairy cows belonging to $\mathrm{O} 130: \mathrm{H} 11$ and $\mathrm{O} 178: \mathrm{H} 19$ serotypes, respectively, were characterized regarding to their cytotoxicity on Vero cells, stx subtypes, presence of sab and typing by multiple-locus variable-number tandem repeat analysis (MLVA). All strains demonstrated a cytotoxic effect, and in 0130:H11 isolates, stX2EDL933 was the predominant subtype. In $0178: \mathrm{H} 19$ isolates the main stx2 subtype was $s t \times 2_{v h a}$. The sab gene was detected in 65 and $24 \%$ of the isolates belonging to $0130: \mathrm{H} 11$ and O178:H19, respectively. Only one MLVA profile was identified among the O130:H11 isolates meanwhile 10 MLVA profiles were detected among the O178:H19 isolates which were grouped in two main clusters. In conclusion, our data show that O130:H11 and 0178:H19 STEC isolates encode virulence factors associated with severe human disease and both serotypes should be considered for routinely testing. Our subtyping experiments showed that isolates could be distinguished based on the $s t x_{2}$ subtype and the presence/absence of sab gene, and for isolates belonging to 0178:H19, also when the MLVA type was considered. However, MLVA subtyping of O130:H11 isolates will require the development of more specific markers.

Keywords: STEC, dairy cattle, MLVA, Shiga toxin

\section{INTRODUCTION}

Shiga toxin-producing E. coli (STEC) cause bloody diarrhea, hemorrhagic colitis (HC) and hemolytic uremic syndrome (HUS) in humans (Pearce et al., 2004; Giugno et al., 2007). Most outbreaks have been attributed to O157:H7 serotype (Mora et al., 2004) but infections with non-O157 serotypes are also being frequently associated with HC and HUS (Bettelheim, 2007). In several countries STEC O157:H7 have been frequently isolated from cattle but several studies in Argentina have detected mainly non-O157:H7 serotypes (Meichtri et al., 2004; Padola et al., 2004; Fernández et al., 2010). Cattle are the main reservoir of STEC and the transmission to humans occurs through the consumption of undercooked meat, non-pasteurized dairy products, and vegetables or water contaminated with feces (Hussein and Sakuma, 2005). Direct contact with cattle and dairy farm environment has been reported also as a possible source for STEC human transmission (Oliver et al., 2005).
The main virulence factor of STEC is the production of Shiga toxins (Stx1 and Stx2) (Paton and Paton, 1998; Gyles, 2007). Stx1 group includes few subtypes, while the Stx2 is a more heterogeneous group and comprises an expanding number of subtypes (such as Stx2EDL933, Stx2vha, Stx2vhb, Stx2O118, Stx2dact, Stx2e, Stx2f, and Stx2g). Stx subtypes differ in their degree of association with HC and HUS cases, being Stx2O118 (formerly identified as Stx2d-Ount), Stx2e, Stx2f, and Stx2g not frequently associated with severe human disease (Friedrich et al., 2002; Karch et al., 2005; Prager et al., 2009, 2011). Other virulence factors that could contribute to the pathogenesis are intimin, encoded by the eae gene and responsible for the intimate attachment of STEC to intestinal epithelial cells, an enterohaemolysin (EhxA), an autoagglutinating adhesin (Saa) and a novel STEC autotransporter (Sab) described for first time in a saa-positive O113:H21 strain, which participates in adhesion and biofilm formation (Herold et al., 2009). The ehxA, saa, and sab genes are 
located in a megaplasmid (Paton and Paton, 1998; Paton et al., 2001; Herold et al., 2009).

In Argentina, O130:H11 and O178:H19 were the most prevalent serotypes isolated from dairy cows (Fernández et al., 2010) and were also identified by Masana et al. (2011) in beef abattoirs and by López et al. (2012) in feedlot cattle. Both serotypes have been isolated from HC and HUS cases in several countries and have been found among human STEC isolates received between 2000-2010 by the CDC National E. coli Reference Laboratory (Blanco et al., 2004; Fremaux et al., 2006; Giugno et al., 2007).

In the present study, we further characterized O130:H11 and O178:H19 STEC isolated by Fernández et al. (2010) from dairy farms regarding their cytotoxicity on Vero cells, stx subtypes, presence of $s a b$ gene and typing by multiple-locus variable-number tandem repeat analysis (MLVA), in order to evaluate the genetic diversity of isolates belonging to these serotypes which are prevalent in dairy cattle.

\section{MATERIALS AND METHODS BACTERIAL STRAINS}

The bacterial strains used in this study were 37 STEC O130:H11 and 25 STEC O178:H19 isolated from dairy cows in five farms (named A, B, C, D, and E) from Argentina (Fernández et al., 2010).

\section{CYTOTOXIC ACTIVITY ON VERO CELLS}

The cytotoxicity of the isolates was evaluated by Vero cells assay. Briefly, each strain was cultured overnight into $25 \mathrm{ml}$ of Microbiological broth (No. 3, Merck) and was centrifuged $120 \times \mathrm{g}\left(10 \mathrm{~min}\right.$ at $\left.4^{\circ} \mathrm{C}\right)$ and the supernatant was centrifuged again $17,228 \times \mathrm{g}\left(10 \mathrm{~min}\right.$ at $\left.4^{\circ} \mathrm{C}\right)$ and identified as $\mathrm{S} 1$. The cell pellet was washed with $\mathrm{PBS}$, resuspended in $3 \mathrm{ml}$ of polymyxin sulfate $(0.1 \mathrm{mg} / \mathrm{ml})$ and incubated $30 \mathrm{~min}$. Polymyxin B-treated cultures were centrifuged at $120 \times \mathrm{g}\left(10 \mathrm{~min}\right.$ at $\left.4^{\circ} \mathrm{C}\right)$. The supernatant was centrifuged at $17,228 \times \mathrm{g}, 10 \mathrm{~min}$ at $4^{\circ} \mathrm{C}$, and was identified as S2. Fifty and $25 \mu \mathrm{l}$ of each one S1 and S2 were inoculated in each one of the 96-well-plates containing $4 \times$ $10^{4}$ freshly trypsinized Vero cells and were incubated $48 \mathrm{~h}$ at $37^{\circ} \mathrm{C}$ in a $5 \% \mathrm{CO}_{2}$ atmosphere. The cell monolayers were fixed with $10 \%(\mathrm{v} / \mathrm{v})$ formaldehyde and then stained with $0.2 \%(\mathrm{w} / \mathrm{v})$ crystal violet in phosphate-buffered saline solution. E. coli EDL933 strain was used as positive control and a strain stx positive without cytotoxic effect as negative control (E. coli serotype O15:H21). Wells having 50\% or greater cytotoxicity, compared to a standard control well were considered positive.

\section{stx SUBTYPING}

The strategy to detect $s t x_{2}$ subtypes was similar to that previously described by Krüger et al. (2011). Briefly, all stx 2 -positive STEC were subjected to PCR with the primer pair VT2-c/VT2-d, and amplification products were independently digested with restriction endonucleases HaeIII, RsaI, and NciI to detect stx 2EDL933, $s t x_{2 \mathrm{vha}}, s t x_{2 \mathrm{vhb}}, s t x_{2 \mathrm{~g}}$, and $s t x_{2 \mathrm{NV} 206}$ (Tyler et al., 1991; Bertin et al., 2001; Krüger et al., 2007). All isolates were also evaluated with the VT2-cm/VT2-f primer set (Pierard et al., 1998) specific for $s t x_{20118}$ (first termed $s t x_{2 \mathrm{~d}}$ by Piérard and renamed st $x_{20118}$ as proposed by Scheutz and Strockbine, 2005). The strains used as positive controls for each subtype and the references corresponding to the primers are detailed in Krüger et al. (2011).

\section{sab GENE}

The detection of the $s a b$ gene was performed by PCR using the primers described by Herold et al. (2009) and the following amplification conditions: initial cycle of $94^{\circ} \mathrm{C}$ for $120 \mathrm{~s}, 30$ cycles with denaturation step $\left(94^{\circ} \mathrm{C}, 30 \mathrm{~s}\right)$, annealing step $\left(54^{\circ} \mathrm{C}\right.$, $30 \mathrm{~s})$ and extension step $\left(68^{\circ} \mathrm{C}, 30 \mathrm{~s}\right)$, and a $60 \mathrm{~s}$ cycle at $72^{\circ} \mathrm{C}$. STEC O20:H19 was used as positive control and Salmonella spp, Staphylococcus aureus, and Pseudomonas aeruginosa as negative controls.

\section{MLVA ASSAY}

We performed an MLVA assay that previously showed a high level of discrimination among STEC isolates belonging to different non-O157:H7 serotypes (Schimmer et al., 2008; Bustamante et al., 2010; Franci et al., 2011). The seven VNTR loci studied in this assay were analyzed as described by Bustamante et al. (2010). Representative alleles were sequenced with an ABI PRISM 3730XL genetic analyzer (Macrogen, Korea). The dendrogram was constructed using the UPGMA clustering method implemented by START Vs. 1.0.5 software (Joley et al., 2001). The alleles were indicated in a string order CVN001-CVN002CVN003-CVN004-CVN007-CVN014-CVN015, named according to the number of tandem repeat sequences. If no amplification product was detected, the allele was designated with an arbitrary number (30).

In all PCR assays, Inbio-Highway (Argentina) DNA polymerase was used.

\section{RESULTS AND DISCUSSION}

Using Vero cell assay, the S1 and S2 supernatants of all isolates from both serotypes demonstrated cytotoxic effect after $48 \mathrm{~h}$ postinoculation on Vero cells.

Among 36 stx 2 -positive O130:H11 isolates, stx 2EDL933 was the predominant subtype (81\%), and the other subtype present was stx $_{2 \mathrm{vhb}}$ (Table 1). Only three isolates harbored both subtypes.

The most frequent $s t x_{2}$ subtype among O178:H19 isolates was $s_{2} x_{2 \text { vha }}(72 \%)$, while $s t x_{2 \text { EDL933 }}$ and $s t x_{2}$ vhb subtypes were found less frequently (20 and $8 \%$, respectively) and no isolates harboring more than one stx 2 subtype were found.

It is interesting to note that the stx 2EDL933-positive strains, belonging to either O130:H11 or O178:H19 serotypes, (Tables 1 and 2) corresponded mainly to isolates harboring the profile stx 1 -stx 2 -ehxA-saa.

The subtypes found in this work have been reported as the predominant $s x t_{2}$-subtypes in bovine STEC strains in Argentina and other countries (Bertin et al., 2001; Brett et al., 2003; Meichtri et al., 2004; Galli et al., 2010; Krüger et al., 2011) and have been associated with the development of $\mathrm{HC}$ and HUS (Friedrich et al., 2002; Persson et al., 2007). In a study performed by Masana et al. (2011) O130:H11 and O178:H19 were also among the most prevalent serotypes found in carcasses and bovine feces sampled 
Table 1 | Origin and virulence genotypes of 0130:H11 isolates.

\begin{tabular}{|c|c|c|c|c|}
\hline $\begin{array}{l}\text { Strain } \\
\text { number }\end{array}$ & Farm & Virulence genotype* & sab & stx 2 subtype \\
\hline 1 & A & stx 1 -ehxA-saa & - & - \\
\hline 2 & A & stx $1-s t x_{2}-e h x A-s a a$ & - & $s t x_{2 v h b}$ \\
\hline 3 & A & stx $1-s t x_{2}-e h x A-s a a$ & - & $s t x_{2 v h b}$ \\
\hline 4 & A & stx $1-s t x_{2}-e h x A-s a a$ & - & $s t x_{2 v h b}$ \\
\hline 5 & A & stx $1-s t x_{2}-e h x A-s a a$ & - & $s t x_{2 E D L 933}$ \\
\hline 6 & A & stx $1-s t x_{2}-e h x A-s a a$ & - & $s t x_{2 E D L 933}$ \\
\hline 7 & A & stx $1-s t x_{2}-e h x A-s a a$ & - & $s t x_{2 E D L 933}$ \\
\hline 8 & $\mathrm{~B}$ & stx $1-s t x_{2}-e h x A-s a a$ & - & $s t x_{2 \mathrm{EDL} 933} s t x_{2 \mathrm{vhb}}$ \\
\hline 9 & B & stx $1-s t x_{2}-e h x A-s a a$ & - & $s t x_{2 \mathrm{EDL} 933} s t x_{2 \mathrm{vhb}}$ \\
\hline 10 & $\mathrm{~B}$ & stx $1-s t x_{2}-e h x A-s a a$ & + & 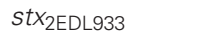 \\
\hline 11 & C & stx $x_{1}-s t x_{2}-e h x A-s a a$ & + & $s t x_{2 E D L 933}$ \\
\hline 12 & C & stx $1-s t x_{2}-e h x A-s a a$ & + & $s t x_{2 E D L 933}$ \\
\hline 13 & C & stx $1-s t x_{2}-e h x A-s a a$ & + & $s t x_{2 E D L 933}$ \\
\hline 14 & C & $s t x_{1}-s t x_{2}-e h x A-s a a$ & + & $s t x_{2 E D L 933}$ \\
\hline 15 & C & stx $x_{1}-s t x_{2}-e h x A-s a a$ & + & $s t x_{2 E D L 933}$ \\
\hline 16 & C & stx $1-s t x_{2}-e h x A-s a a$ & + & $s t x_{2 E D L 933}$ \\
\hline 17 & C & $s t x_{1}-s t x_{2}-e h x A-s a a$ & + & $s t x_{2 E D L 933}$ \\
\hline 18 & C & $s t x_{1}-s t x_{2}-e h x A-s a a$ & + & $s t x_{2 E D L 933}$ \\
\hline 19 & C & $s t x_{1}-s t x_{2}-e h x A-s a a$ & + & $s t x_{2 E D L 933}$ \\
\hline 20 & C & $s t x_{1}-s t x_{2}-e h x A-s a a$ & + & 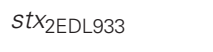 \\
\hline 21 & C & $s t x_{1}-s t x_{2}-e h x A-s a a$ & + & $s t x_{2 E D L 933}$ \\
\hline 22 & $\mathrm{D}$ & $s t x_{1}-s t x_{2}-e h x A-s a a$ & + & $s t x_{2 \mathrm{EDL} 933} s t x_{2 \mathrm{vhb}}$ \\
\hline 23 & D & $s t x_{1}-s t x_{2}-e h x A-s a a$ & - & $s t x_{2 E D L 933}$ \\
\hline 24 & D & $s t x_{1}-s t x_{2}-e h x A-s a a$ & + & 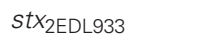 \\
\hline 25 & $\mathrm{D}$ & stx $1-s t x_{2}-e h x A-s a a$ & + & $s t x_{2 E D L 933}$ \\
\hline 26 & $\mathrm{D}$ & stx $x_{1}-s t x_{2}-e h x A-s a a$ & - & $s t x_{2 v h b}$ \\
\hline 27 & D & stx $x_{1}-s t x_{2}-e h x A-s a a$ & + & $s t x_{2 v h b}$ \\
\hline 28 & D & stx $x_{1}-s t x_{2}-e h x A-s a a$ & + & $s t x_{2 E D L 933}$ \\
\hline 29 & D & stx $x_{1}-s t x_{2}-e h x A-s a a$ & + & st $x_{2 E D L 933}$ \\
\hline 30 & D & stx $x_{1}-s t x_{2}-e h x A-s a a$ & + & 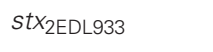 \\
\hline 31 & D & $s t x_{1}-s t x_{2}-e h x A-s a a$ & - & $s t x_{2 \mathrm{vhb}}$ \\
\hline 32 & D & stx $x_{1}-s t x_{2}-e h x A-s a a$ & + & 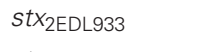 \\
\hline 33 & $\mathrm{D}$ & stx $x_{1}-s t x_{2}-e h x A-s a a$ & + & $s t x_{2 E D L 933}$ \\
\hline 34 & $\mathrm{D}$ & $s t x_{1}-s t x_{2}-e h x A-s a a$ & + & $s t x_{2 E D L 933}$ \\
\hline 35 & D & stx $1-s t x_{2}-e h x A-s a a$ & - & $s t x_{2 E D L 933}$ \\
\hline 36 & D & stx $x_{1}-s t x_{2}-e h x A-s a a$ & + & $s t x_{2 E D L 933}$ \\
\hline 37 & $E$ & stx $1-s t x_{2}-e h x A-s a a$ & + & $s t x_{2 E D L 933}$ \\
\hline
\end{tabular}

*Previously determined (Fernández et al., 2010).

at abattoirs in Argentina. In that study, O130:H11 isolates presented the same virulence genotypes (in regard to the presence of $s t x_{1}, s t x_{2}$ subtypes, ehxA and saa) as the ones detected in the present report. Regarding to O178:H19, some virulence genotypes (stx $\left.x_{2 \mathrm{vha}} ; s t x_{1}-s t x_{2 \mathrm{EDL} 933}-\mathrm{eh} x A-s a a ; s t x_{2 \mathrm{vhb}}\right)$ found by Masana et al. (2011) were detected also in the present study, but there were other profiles $\left(s t x_{2 \mathrm{NT}} ; s t x_{2 \mathrm{EDL} 933}-s t x_{2 \mathrm{vha}}\right)$ not shared between these studies.

The gene encoding Sab, a protein which mediates biofilm formation and promotes intestinal adherence, was detected in 65\% of the isolates belonging to O130:H11. This study is the first,
Table 2 | Origin and characterization of 0178:H19 isolates.

\begin{tabular}{|c|c|c|c|c|c|}
\hline $\begin{array}{l}\text { Strain } \\
\text { number }\end{array}$ & Farm & Virulence genotype* & sab & $\begin{array}{l}\text { stx }_{2} \\
\text { subtype }\end{array}$ & $\begin{array}{l}\text { MLVA } \\
\text { profile }\end{array}$ \\
\hline 1 & A & $s t x_{2}$ & - & $s t x_{2 v h a}$ & $\mathrm{l}_{1}$ \\
\hline 2 & A & $s t x_{2}$ & - & $s t x_{2 v h a}$ & $\mathrm{l}_{1}$ \\
\hline 3 & A & $s t x_{2}$ & - & stx 2 vha & $\mathrm{l}_{1}$ \\
\hline 4 & A & $s t x_{2}$ & - & stx 2 vha & $\mathrm{I}_{1}$ \\
\hline 5 & A & $s t x_{2}$ & - & $s t x_{2 v h a}$ & $\mathrm{I}_{2}$ \\
\hline 6 & C & stx 2 & - & stx 2 vha & $I_{3}$ \\
\hline 7 & C & stx 2 & - & stx 2 vha & $\mathrm{I}_{5}$ \\
\hline 8 & $\mathrm{D}$ & $s t x_{2}$ & - & $s t x_{2 v h a}$ & $\mathrm{l}_{1}$ \\
\hline 9 & $\mathrm{D}$ & $s t x_{2}$ & + & $s t x_{2 v h b}$ & $\mathrm{H}_{2}$ \\
\hline 10 & $E$ & $s t x_{2}$ & - & $s t x_{2 v h a}$ & $\mathrm{l}_{1}$ \\
\hline 11 & $E$ & $s t x_{2}$ & + & $s t x_{2 \mathrm{EDL}} 933$ & $\mathrm{II}_{4}$ \\
\hline 12 & $E$ & $s t x_{2}$ & - & $s t x_{2 v h b}$ & $\mathrm{I}_{4}$ \\
\hline 13 & $\mathrm{E}$ & $s t x_{2}$ & - & $s t x_{2 v h a}$ & $\mathrm{I}_{2}$ \\
\hline 14 & $\mathrm{E}$ & stx 2 & - & stx 2 vha & $\mathrm{I}_{1}$ \\
\hline 15 & B & $s t x_{2}$ & - & stx 2 vha & $\mathrm{I}_{3}$ \\
\hline 16 & A & $s t x_{2}$ & - & $s t x_{2 \text { vha }}$ & $\mathrm{I}_{2}$ \\
\hline 17 & C & stx $x_{1}-s t x_{2}-e h x A-s a a$ & + & st $x_{2 E D L 933}$ & $\mathrm{II}_{3}$ \\
\hline 18 & C & $s t x_{1}-s t x_{2}-e h x A-s a a$ & + & $s t x_{2 E D L 933}$ & $\mathrm{I}_{5}$ \\
\hline 19 & $\mathrm{D}$ & $s t x_{2}$ & - & $s t x_{2 \mathrm{vha}}$ & $\mathrm{I}_{2}$ \\
\hline 20 & $\mathrm{D}$ & stx $x_{1}-s t x_{2}-e h x A-s a a$ & + & $s t x_{2 \mathrm{EDL933}}$ & $\mathrm{I}_{2}$ \\
\hline 21 & $\mathrm{D}$ & st $x_{2}-e h x A-s a a$ & - & $s t x_{2 v h a}$ & $I_{2}$ \\
\hline 22 & $\mathrm{D}$ & st $x_{2}$ & - & stx 2 vha & $\mathrm{I}_{1}$ \\
\hline 23 & $E$ & stx $x_{1}-s t x_{2}-e h x A-s a a$ & + & $s t x_{2 E D L 933}$ & $\mathrm{H}_{1}$ \\
\hline 24 & C & stx 2 & - & stx 2 vha & $\mathrm{I}_{1}$ \\
\hline 25 & C & $s t x_{2}$ & - & stx 2 vha & $\mathrm{l}_{1}$ \\
\hline
\end{tabular}

*Previously determined (Fernández et al., 2010).

to our knowledge, to describe O130:H11 as a serotype carrying $s a b$. In O178:H19 isolates sab was detected in 24\% of the isolates (Table 2). Buvens et al. (2010) did not detect sab in a STEC O178:H19 strain isolated from HUS. All sab-positive STEC strains identified to date were also positive for $e h x$ as well as saa, all genes located in a megaplasmid, noteworthy, in the present study some of the O178:H19 isolates were $s a b$-positive but negative for $e h x \mathrm{~A}$ and saa.

Most of the MLVA loci could be amplified, although there were differences between serotypes. To our knowledge this is the first time that STEC O130:H11 is typed by MLVA and notably, only one MLVA profile (5-2-30-9-8-30-6) was detected among these isolates. We have used this MLVA assay to subtype several isolates belonging to different non-O157:H7 serotypes and we found a high level of discrimination (Bustamante et al., 2010; Franci et al., 2011). Other authors have also applied this protocol to successfully resolve outbreaks due to a non-O157 strain (Schimmer et al., 2008). In our experience, this is the first time that all isolates from a same serotype and different origin present a unique MLVA profile. The lack of diversity found in this serotype would indicate that the chosen VNTR loci are not variable enough for typing O130:H11 strains since they did show variability in relation with the presence/absence of $s a b$ and also with the st $x 2$ subtype present. 
Therefore, there is a need to identify VNTR loci that are variable among STEC strains belonging to this serotype.

On the other hand, among the 25 O178:H19 isolates, 10 MLVA profiles were detected, which were grouped in two main clusters (Figure 1). A relationship could not be found with regard to MLVA profiles and farm origin (Table 2). Cluster I included isolates from all the farms, and cluster II, isolates from dairy farms C, $\mathrm{D}$, and $\mathrm{E}$. A high variability was found among isolates from farms $\mathrm{C}$ and $\mathrm{E}$, detecting in each farm 5 MLVA profiles among 6 isolates (Table 2). All isolates belonging to clade I, were sab-negative and, with the exception of isolate 12 , they presented the subtype $s t x_{2 \text { vha }}$ (Table 2). Clade II was the most variable, presenting five different profiles among six isolates. Moreover, isolates 9 and 20 shared the MLVA profile but not their virulence profile. Within this clade, all the isolates were $s a b$-positive and carried $s t x_{2 E D L 933}$, with the exception of isolate 9 (positive for $s a b$ but negative for that $s t x_{2}$ subtype) (Table 2). Although a relationship between the MLVA profile and the stx 2 subtype is not expected, with the exception of

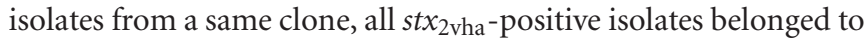
cluster I and all stx $x_{\mathrm{EDL} 933}$-positive isolates, to cluster II. Regarding isolates carrying $s t x_{2 \mathrm{vhb}}$, one belonged to cluster I and the other to cluster II. Noteworthy, all the MLVA profiles present in these isolates were quite different from the ones detected previously in STEC O178:H19 isolated from minced meat of the same geographic region (Franci et al., 2011). Taking into account all these results, a high genetic variability was evidenced among isolates belonging to this serotype. Our results showed different STEC O178:H19 clonal lineages and determined that some clones may be present in more than one farm.

\section{CONCLUSION}

The data suggest differences in the genetic variability for the two serotypes. It could be assessed when the stx 2 subtype and the presence/absence of $s a b$ gene were taken into account, and for isolates belonging to O178:H19, also when the MLVA type was considered. The MLVA typing assay chosen seems not suitable for detecting genetic differences among O130:H11 STEC isolates, and further loci need to be analyzed.

STEC non-O157 serotypes are nowadays frequently associated with outbreaks and sporadic cases of HUS and particularly, O130:H11 and O178:H19 STEC have been isolated from human patients. In our study isolates from dairy cows belonging to these serotypes possess virulence characteristics associated with the development of severe disease in humans and

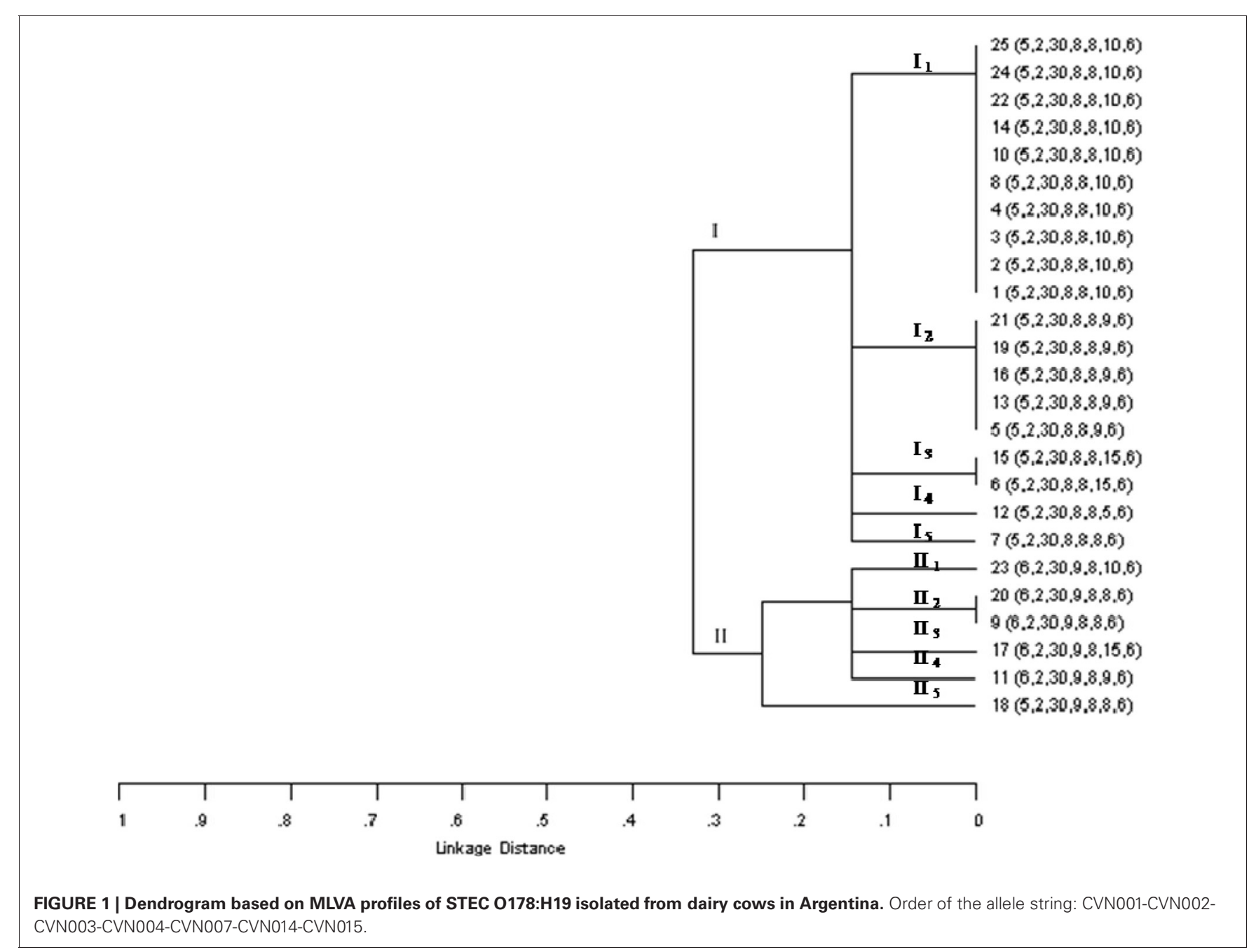


it would be desirable to consider them in the group of serotypes routinely investigated.

\section{ACKNOWLEDGMENTS}

Authors thank María R. Ortiz for her technical assistance. This work was supported by FONCYT PICT 2010 PROY 1655,

\section{REFERENCES}

Bertin, Y., Boukhors, K., Livrelli, V., and Martin, C. (2001). stx2 subtyping of shiga toxin-producing Escherichia coli isolated from cattle in France detection of new stx2 subtype and correlation with additional virulence factors. J. Clin. Microbiol. 39, 3060-3065.

Bettelheim, K. (2007). The non-O157 shiga-toxigenic (verocytotoxigenic) Escherichia coli; under-rated pathogens. Crit. Rev. Microbiol. 33, 67-87.

Blanco, M., Blanco, J. E., Mora, A., Dahbi, G., Alonso, M. P., González, E. A., et al. (2004). Serotypes, virulence genes, and intimin types of Shiga toxin producing Escherichia coli isolates from cattle in Spain and identification of a new intimin variant gene (eae). J. Clin. Microbiol. 42, 645-651.

Brett, K. N., Hornitzky, M. A., Bettelheim, K. A., Walker, M. J., and Djordjevic, S. P. (2003). Bovine non-O157 Shiga-toxin 2-containing Escherichia coli isolates commonly possess stx2-EDL933 and/or stx2vhb subtypes. J. Clin. Microbiol. 41, 2716-2722.

Bustamante, A. V., Sanso, A. M., Lucchesi, P. M. A., and Parma, A. E. (2010). Genetic diversity of O157:H7 and non-O157 verocytotoxigenic Escherichia coli from Argentina inferred by multiple-locus variablenumber tandem repeat analysis (MLVA). Int. J. Med. Microbiol. 300, 212-217.

Buvens, G., Lauwers, S., and Piérard, D. (2010). Prevalence of subtilase cytotoxin in verocytotoxinproducing Escherichia coli isolated from humans and raw meats in Belgium. Eur. J. Clin. Microbiol. Infect. Dis. 29, 1395-1399.

Fernández, D., Irino, K., Sanz, M. E., Padola, N. L., and Parma, A. E. (2010). Characterization of Shiga toxin-producing Escherichia coli isolated from dairy cows in Argentina. Lett. Appl. Microbiol. 51, 377-382.

Franci, T., Sanso, A. M., Bustamante, A. V., Lucchesi, P. M. A., and Parma, A. E. (2011). Genetic characterization of non-O157 verocytotoxigenic Escherichia coli isolated from raw beef products using multiple-locus variablenumber tandem repeat analysis (MLVA). Foodborne Pathog. Dis. 8, 1019-1023.

Fremaux, B., Raynaud, S., Beutin, L., and Vernozy Rozand, C. (2006). Dissemination and persistence of Shiga toxin-producing Escherichia coli (STEC) strains on French dairy farms. Vet. Microbiol. 117, 180-191.

Friedrich, A. W., Bielaszewska, M., Zhang, W. L., Pulz, M., Kuczius, T., Ammon, A., et al. (2002). Escherichia coli harboring Shiga toxin 2 gene variants: frequency and association with clinical symptoms. J. Infect. Dis. 185 , 74-84.

Galli, L., Miliwebsky, E., Irino, K., Leotta, G., and Rivas, M. (2010). Virulence profile comparison between LEE-negative Shiga toxin-producing Escherichia coli (STEC) strains isolated from cattle and humans. Vet. Microbiol. 143, 307-313.

Giugno, S. M., Bibiloni, N., Rahman, R., Miliwebsky, E., Chinen, I., and Rivas, M. (2007). Association between uremic hemolytic syndrome and infection by Shiga toxin-producing Escherichia coli. Acta Bioquím. Clín. Latinoam. 41, 27-33.

Gyles, C. (2007). Shiga toxin producing Escherichia coli: an overview. J. Animal Sci. 85, E42-E62.

Herold, S., Paton, J. C., and Paton, A. W. (2009). Sab, a novel autotransporter of locus of enterocyte effacement-negative shiga-toxigenic Escherichia coli O113:H21, contributes to adherence and biofilm formation. Infect. Immun. 77, 3234-3243.

Hussein, H., and Sakuma, T. (2005). Prevalence of Shiga toxin-producing Escherichia coli in dairy cattle and their products. J. Dairy Sci. 88, 450-465.

Joley, K. A., Feil, E. J., Chan, M. S., and Maiden, M. C. (2001). Sequence type analysis and recombinational tests (START). Bioinformatics 17, 1230-1231.

CIC and SECYT-UNCPBA. Nora L. Padola is member of the Scientific Research Commission Prov. Buenos Aires (CIC). Daniel Fernández is a holder of a fellowship from CONICET, Alejandra Krüger, Ana V. Bustamante, A. Mariel Sanso, Analía I. Etcheverría, and Paula M. A. Lucchesi are members of the Research Career of CONICET.

Karch, H., Tarr, P. I., and Bielaszewska, M. (2005). Enterohaemorrhagic Escherichia coli in human medicine. Int. J. Med. Microbiol. 295, 405-418.

Krüger, A., Lucchesi, P. M. A., and Parma, A. E. (2007). Evaluation of $v t$-subtyping methods for identifying $v t 2 \mathrm{~g}$ in verotoxigenic Escherichia coli. J. Med. Microbiol. 56, 1474-1478.

Krüger, A., Lucchesi, P. M. A., and Parma, A. E. (2011). Verotoxins in bovine and meat verotoxinproducing Escherichia coli isolates: type, number of variants, and relationship to cytotoxicity. Appl. Environ. Microbiol. 77, 73-79.

López, O., Duverne, L., Chinen, I., Carbonari, C., Mazieres, J., Deza, N., et al. (2012). Shedding and characterization non-O157 of Shiga toxin-producing Escherichia coli strains isolated from beef cattle in one feedlot of Argentina. VTEC (2012). 8th International Symposium on Shiga toxin (verocytotoxin) producing Escherichia coli Infections. Abstract book, P196, 202.

Masana, M. O., D'Astek, B. A. Palladino, P. M., Galli, L., Del Castillo, L. L., Carbonari, C., et al. (2011). Genotypic characterization of non-O157 Shigatoxin-producing Escherichia coli in beef abattoirs of Argentina. J. Food Prot. 12, 2008-2017.

Meichtri, L., Miliwebsky, E., Gioffré, A., Chinen, I., Baschkier, A., Chillemi, G., et al. (2004). Shigatoxin-producing Escherichia coli in healthy young beef steers from Argentina: prevalence and virulence properties. Int. J. Food Microbiol. 96, 189-198.

Mora, A., Blanco, M., Blanco, J. E., Alonso, M. P., Dhabi, G., ThomsonCarter, F., et al. (2004). Phage types and genotypes of Shiga toxin-producing Escherichia coli O157:H7 isolates from humans and animals in Spain: identification and characterization of two predominating phage types (PT2 and PT8). J. Clin. Microbiol. 42, 4007-4015.

Oliver, S. P., Jayarao, B. M., and Almeida, R. A. (2005). Foodborne pathogens in milk and the dairy farm environment: food safety and public health implications. Foodborne Pathog. Dis. 2, 115-129.

Padola, N. L., Sanz, M. E., Blanco, J. E., Blanco, M., Blanco, J., Etcheverria, A. I., et al. (2004). Serotypes and virulence genes of Shigatoxigenic Escherichia coli (STEC) isolates from a feedlot in Argentina. Vet. Microbiol. 100, 3-9.

Paton, A. W., and Paton, J. C. (1998). Detection and characterization of Shiga Toxigenic Escherichia coli by using multiplex PCR assays for stx1, stx2, eaeA, enterohemorrhagic, E. coli HlyA, rfbO111 and rfbO157. J. Clin. Microbiol. 36, 598-602.

Paton, A. W., Srimanote, P., Woodrow, M. C., and Paton, J. S. (2001). Characterization of Saa, a novel autoagglutinating adhesin produced by locus of enterocyte effacement-negative Shiga toxigenic Escherichia coli strains that are virulent for humans. Infect. Immun. 69, 6999-7009.

Pearce, M. C., Jenkins, C., Vali, L., Smith, A. W., Knight, H. I., Cheasty, T., et al. (2004). Temporal shedding patterns and virulence factors of Escherichia coli serogrups O26, O113, O111, O145 and O157in a cohort of beef calves and dairy dams. Appl. Environ. Microbiol. 70, 1708-1716.

Persson, S., Olsen, K. E. P., Scheutz, F., Krogfelt, K. A., and GernerSmidt, P. (2007). A method for fast and simple detection of major diarrheagenic Escherichia coli in the routine diagnostic laboratory. Eur. J. Clin. Microbiol. Infect. Dis. 13, 516-524.

Pierard, D., Muyldermans, G., Moriau, L., Stevens, D., and Lauwers, S. (1998). Identification of new verocytotoxin Type 2 variant B-subunit genes in human and animal Escherichia coli isolates. J. Clin. Microbiol. 36, 3317-3322.

Prager, R., Fruth, A., Busch, A., and Tietze, E. (2011). Comparative analysis of virulence genes, genetic diversity, and phylogeny of Shiga 
toxin $2 \mathrm{~g}$ and heat-stable enterotoxin STIa encoding Escherichia coli isolates from humans, animals, and environmental sources. Int. J. Med. Microbiol. 301, 181-191.

Prager, R., Fruth, A., Siewert, U., Strutz, U., and Tschäpe, H. (2009). Escherichia coli encoding Shiga toxin $2 \mathrm{f}$ as an emerging human pathogen. Int. J. Med. Microbiol. 299, 343-353.

Scheutz, F., and Strockbine, N. A. (2005). "Escherichia," in Bergey's Manual of Systematic Bacteriology, eds G. M. Garrity, D. J. Brenner, N. R. Krieg, and J. T.
Staley (New York, NY: Springer), 607-624.

Schimmer, B., Nygard, K., Eriksen, H. M., Lassen, J., Lindstedt, B. A., Brandal, L. T., et al. (2008). Outbreak of haemolytic uraemic syndrome in Norway caused by stx2-positive Escherichia coli O103:H25 traced to cured mutton sausages. BMC Infect. Dis. 8:41. doi: 10.1186/1471-2334-8-41

Tyler, S. D., Johnson, W., Lior, H., Wang, G., and Rozee, K. R. (1991). Identification of verotoxin type 2 variant B subunit genes in E. coli by the polymerase chain reaction and restrictionfragment length polymorphism analysis. J. Clin. Microbiol. 29, 1339-1343.

Conflict of Interest Statement: The authors declare that the research was conducted in the absence of any commercial or financial relationships that could be construed as a potential conflict of interest.

Received: 02 November 2012; accepted: 19 February 2013; published online: 08 March 2013.

Citation: Fernández D, Krüger A, Polifroni $R$, Bustamante $A V$, Sanso AM, Etcheverría AI, Lucchesi PMA, Parma AE and Padola NL
(2013) Characterization of Shiga toxinproducing Escherichia coli O130:H11 and O178:H19 isolated from dairy cows. Front. Cell. Infect. Microbiol. 3:9. doi: 10.3389/fcimb.2013.00009

Copyright (c) 2013 Fernández, Krüger, Polifroni, Bustamante, Sanso, Etcheverría, Lucchesi, Parma and Padola. This is an open-access article distributed under the terms of the Creative Commons Attribution License, which permits use, distribution and reproduction in other forums, provided the original authors and source are credited and subject to any copyright notices concerning any third-party graphics etc. 